\title{
Pollination in the marine realm: microsatellites reveal high outcrossing rates and multiple paternity in eelgrass Zostera marina
}

\author{
THORSTEN B. H. REUSCH \\ Max-Planck-Institut für Limnologie, August-Thienemann-Strasse 2, 24306 Plön, Germany
}

\begin{abstract}
The mating system was examined in two annual populations of eelgrass (Zostera marina), a marine angiosperm displaying subaqueous pollination. Multilocus genotyping using microsatellite DNA markers allowed the assessment of the pollen source based on single progeny as units of observation. Outcrossing was detectable by the presence of non-maternal alleles at one or more of the loci. In outcrossing cases, three microsatellite alleles were present in unripe seeds, consisting of both maternal alleles and the paternal allele composing the triploid primary endosperm. In ripe seeds, only the diploid embryonal genotype was amplifiable by PCR. Two intertidal populations situated in the German Wadden Sea were almost entirely outcrossing $(t \pm \mathrm{SE} 0.96 \pm 0.03, \quad N=60$ and $0.97 \pm 0.029, N=37$ ). Because of the high polymorphism displayed by the eight chosen microsatellites, representing a total of 69 and 76 alleles, the likelihood of erroneously inferring selfing was small $(\alpha=0.0026$ and 0.0007$)$. In order to study the correlation of paternity, the coefficient of relatedness was determined within sibships. Relatedness $(r \pm \mathrm{SE})$ was calculated as $0.357 \pm 0.059$ and $0.343 \pm 0.037$, indicating multiple paternities within inflorescences. Small amounts of tissue $(\leq 0.1 \mathrm{mg})$ such as the developing seeds of recently fertilized ovules, were sufficient for PCRamplification. Hence, PCR-based methods, such as multilocus microsatellite genotyping, allow the detection of pollen origin early in the development of progeny. They will be useful to distinguish postfertilization processes such as selective abortion and germination from other prefertilization determinants of plant mating systems.
\end{abstract}

Keywords: hydrophily, microsatellites, outcrossing rate, relatedness, selfing, Zostera marina.

\section{Introduction}

The mating system of a plant describes how female and male gametes unite and transmit genetic information to the next generation. Information on the mating system is central for explaining the origin of within- and between population structure (Hamrick \& Godt, 1991), and the evolutionary potential of a plant species (Charlesworth \& Charlesworth, 1987). One major component of the mating system is the origin of pollen fertilizing an ovule. It may stem either from male organs or flowers of the hermaphroditic maternal plant (resulting in selfing), or from a different plant, resulting in outcrossed progeny.

Correspondence. E-mail: reusch@mpil-ploen.mpg.de (C) 2000 The Genetical Society of Great Britain.
Hydrophilous pollination, the analogue of windpollination on land, occurs in only eight families of flowering plants. It is thought to be a derived trait which evolved polyphyletically and is associated with a secondary adaptation to the submerged habitat (Les, 1988). Data on the mating system are available for only two species with subaqueous pollination, the seagrass species Zostera marina and Posidonia australis (Ruckelshaus, 1995; Waycott \& Sampson, 1997). The lack of knowledge on the reproductive biology of aquatic angiosperms seriously impairs understanding of the evolutionary processes in these plant taxa (Barrett et al., 1993).

For estimating the relative contribution of inbreeding and outcrossing, codominantly inherited genetic markers facilitate the distinction between maternal (selfed) and foreign (outcrossed) alleles in offspring 
genotypes. To date, most direct studies on plant mating systems have utilized the polymorphism of electrophoretically separable allozymes. The amount of genetic polymorphism displayed by these markers is often limited. Maximum-likelihood techniques using several progeny arrays each having many offspring have been developed to compensate for the lack of polymorphism (e.g. Brown \& Allard, 1970; Ritland \& Jain, 1981; Ritland, 1984).

Except for one study in Callitriche hermaphroditica (Philbrick, 1993), the potential offered by DNA-based markers for studying mating systems has not been realized. In particular, in aquatic angiosperms which display limited polymorphism in traditional Mendelian inherited markers (i.e. allozymes; Les, 1988), DNA microsatellites may be alternatives to allozymes for mating system studies. The utility and statistical power of the method to infer correctly the origin of pollen was tested for progeny in two annual populations of eelgrass, Zostera marina, the dominant seagrass of shallow coastal zones of the northern hemisphere. For eelgrass, several polymorphic microsatellite loci have recently been described, allowing an assessment of its mating system to augment the sparse information existing for hydrophilous flowering plants. An additional goal of this study was to investigate whether recently pollinated female flowers with unripe and small embryos could be genotyped for several microsatellite loci, taking advantage of the capability of PCR to amplify only a few DNA copies.

\section{Materials and methods}

\section{Study organism and sites}

The study species, eelgrass (Zostera marina L.), is a marine angiosperm distributed widely through shallow sedimentary coastlines of Europe, North America and Asia. Reproductive shoots carry up to 15 inflorescences that ripen successively (De Cock, 1980). Each inflorescence carries a row of up to 25 alternating male and female flowers. Female flowers have only one ovule; their number thus corresponds to the maximal number of seeds produced. Pollen grains are thread-like and transported passively to female stigmata by water movement (Cox, 1993; Ackerman, 1997a,b). Within each inflorescence, male flowers ripen prior to the female flowers, which is commonly interpreted as an adaptation to avoid self-fertilization and to ensure outcrossing (De Cock, 1980). Eelgrass is self-compatible as demonstrated in artificial selfing trials (Ruckelshaus, 1995).

I studied the mating systems of two eelgrass populations (Hooge, hereafter $\mathrm{HO}, 54^{\circ} 34.2^{\prime} \mathrm{N}, 8^{\circ} 30.9^{\prime} \mathrm{E}$; and Munkmarsch, MU, $\left.54^{\circ} 54.5 \mathrm{~N}, 8^{\circ} 22.1^{\prime} \mathrm{E}\right)$ situated in the intertidal zone of the German Wadden Sea. In contrast to many other locations where plants are perennial and reproduce both clonally and sexually, sexual reproduction predominates in both study populations as they overwinter entirely through seeds. Clonal propagation is restricted to ramet clusters of at most 20 shoots during one growth season (April to September), of which a maximum of five may flower at the same time (T.B.H. Reusch, unpubl. data). In both populations, 50 plants were sampled at random positions within a rectangular plot of $20 \times 60 \mathrm{~m}$ at minimal distances of $1 \mathrm{~m}$. Twenty fruiting shoots were chosen at random for a joint analysis of maternal and offspring genotype. In each of the selected maternal plants, three progeny stemming from the same inflorescence were analysed (total number of genotyped offspring $N=60$ and 40 at $\mathrm{HO}$ and $\mathrm{MU}$, respectively). Allele frequencies in the population were estimated based on the assay of all 50 adult plants.

\section{Sample extraction and genotyping}

The assessment of the mating system is based on a comparison of microsatellite multilocus genotypes between mothers and single offspring. Previously, 12 polymorphic markers for eelgrass Zostera marina have been developed (Reusch et al., 1999; Reusch, 2000), eight of which were selected for this study based on their within-population polymorphism (Table 1). All microsatellite loci are perfect dinucleotide repeats, always differ in allele size by multiples of one repeat unit (i.e. two base-pairs), and possess no null-alleles. They conform to Mendelian inheritance and are not linked in both populations (T.B.H. Reusch, unpubl. data).

Leaf samples and inflorescences containing ripening ovules were preserved through drying on silica-gel. Between 0.02 and $2 \mathrm{mg}$ of dried plant tissue (leaf), or

Table 1 Microsatellite loci used for estimation of mating system in Zostera marina (eelgrass), their number of alleles per population, and the Gen-Bank accession numbers. HO, Hooge population; MU, Munkmarsch population

\begin{tabular}{lccc}
\hline \multirow{2}{*}{$\begin{array}{l}\text { Microsatellite } \\
\text { locus }\end{array}$} & \multicolumn{2}{c}{ No. of alleles } & \\
\cline { 2 - 3 } & HO & MU & $\begin{array}{c}\text { Gen-Bank } \\
\text { accession no. }\end{array}$ \\
\hline Zosmar CT-3 & 13 & 11 & AJ009898 \\
Zosmar GA-2 & 8 & 10 & AJ009900 \\
Zosmar GA-6 & 4 & 5 & AJ009904 \\
Zosmar CT-12 & 4 & 5 & AJ249303 \\
Zosmar CT-19 & 4 & 4 & AJ249304 \\
Zosmar CT-20 & 5 & 7 & AJ249306 \\
Zosmar CT-17H & 16 & 14 & AJ249307 \\
Zosmar CT-35 & 15 & 20 & AJ249305 \\
Total & 69 & 76 & \\
\hline
\end{tabular}

(c) The Genetical Society of Great Britain, Heredity, 85, 459-464. 
$0.01-0.2 \mathrm{mg}$ (embryo) were placed in $50-100 \mu \mathrm{L}$ of a $5 \%$ (wt/vol) aqueous suspension (HPLC-water) of Chelex 100 Resin (Biorad, Hercules, California) (Walsh et al., 1991). When analysing seeds, their seed coat was removed prior to DNA extraction. After resuspension of Chelex beads and tissue, samples were frozen for 1-24 h to break the cell walls. Samples were then incubated for $1 \mathrm{~h}$ at $56^{\circ} \mathrm{C}$. After $9 \mathrm{~min}$ at $100^{\circ} \mathrm{C}$, the suspension was rapidly cooled on ice, vigorously vortexed for $30 \mathrm{~s}$, and then centrifuged for $2 \mathrm{~min}$ at $800 \mathrm{~g}$. The supernatant was stored at $-20^{\circ} \mathrm{C}$ and $1 \mu \mathrm{L}$ was used for DNA amplification. PCR-amplification conditions and microsatellite genotyping followed the protocols given in Reusch (2000) and Reusch et al. (2000); 33 PCR cycles were generally used for the amplification of products.

\section{Statistical analysis}

Embryonal genotypes were interpreted as outcrossed if a novel allele not present in the maternal genotype was observed at any of the eight microsatellite loci. Assuming that there is no mutation, this is always a true inference. Those embryos displaying only maternal alleles at all loci could result either from selfing (true inference), or from a nondiscernible outcrossing event (erroneous inference). In a given population sample of maternal plants, the overall likelihood of a nondiscernible outcrossing event $\alpha$ is a function of the frequency of the maternal genotypes $P$ and the allele frequencies $p$ in the population (Shaw et al., 1981). Following the notation of Weir (1996) the single-locus probability of not detecting an outcrossing event is:

$\beta_{l}=\sum_{u} P_{l u, l u} p_{l u}+\sum_{u} \sum_{u \neq v} P_{l u, l v}\left(p_{l u}+p_{l v}\right)$

where (always at locus $l$ ) $P_{l u, l u}$ is the frequency of homozygous genotypes carrying alleles with the population frequency $p_{l u}$, and $P_{l u, l v}$ is the frequency of heterozygous genotypes with the respective allele frequencies $p_{l u}$ and $p_{l v}$. The multilocus probability of a nondetectable outcrossing event $\alpha$ is the product of all single-locus probabilities $\beta_{l}$

$\alpha=\prod_{i} \beta_{l}$

In order to study the correlation of paternity, the coefficient of relatedness was determined within sibships using the software RELATEDNESS 5.0.5 (Goodnight \& Queller, 1999). Eleven (MU) and 15 (HO) sibships, each containing three embryos from the same inflorescence, were tested for relatedness ( $r$ of Queller \& Goodnight, 1989) against the allele frequencies in the respective population, determined in 50 adult individuals. Confi- dence intervals of $r$ were calculated by jack-knifing over sibships.

\section{Results}

All maternal plants, and 60/60 HO and 37/40 MU offspring, could be amplified by PCR at all microsatellite loci. In unripe ovules (ovule dry weight $0.01-0.2 \mathrm{mg}$ ), the developing embryo displayed a triploid genotype if the mother was heterozygous and the pollen origin was outcrossing. Both maternal alleles and the novel allele from the parent pollen were successfully amplified by PCR and were present in the electropherogram (Fig. 1a). Angiosperms retain both maternal alleles in the embryo sac (primary endosperm) of developing fruits. The pollen containing two sperm cells fertilizes both, the diploid maternal embryo sac cell resulting in a triploid primary endosperm, and the female gamete resulting in the diploid zygote. In ripe seeds shortly

\section{Developing embryo}

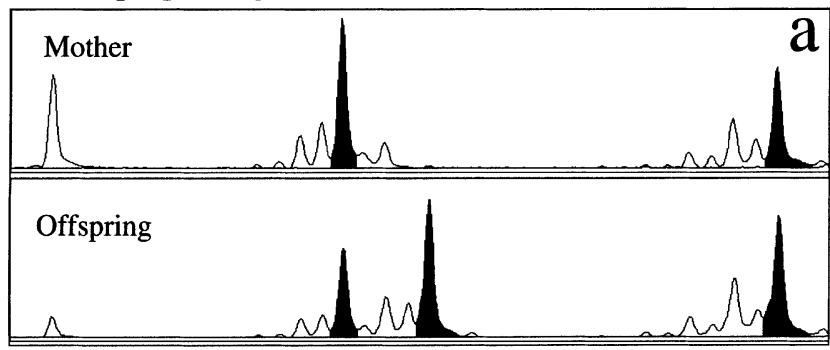

Ripe seed

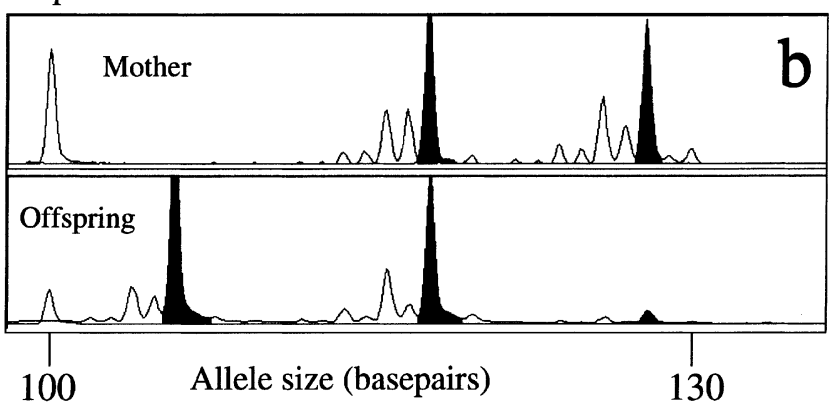

Fig. 1 Eelgrass Zostera marina: comparison of mother and progeny genotype at one microsatellite locus (Zosmar CT-3) using fluorescently labelled PCR-products visualized on an ABI 377 automated sequencer (Applied Biosystem). The $x$-axis gives the fragment size in base pairs, the $y$-axis represents the fluorescent signal in arbitrary units. (a) Mother and developing embryo shortly after fertilization of female flower; mother displays genotype $114 / 134 \mathrm{bp}$, offspring has triploid genotype $114 / 118 / 134 \mathrm{bp}$. The new allele at $118 \mathrm{bp}$ indicates outcrossing. (b) Mother and ripe seed. The maternal allele at $128 \mathrm{bp}$ has been dropped during meiosis and is hardly amplifiable in offspring. A new allele at $106 \mathrm{bp}$ indicates outcrossing. In both panels, the unfilled peak at $100 \mathrm{bp}$ is an internal lane standard. 
before detachment, only the two alleles of the novel offspring genotype were detectable, suggesting that at this stage, the number of DNA copies of the nonpreserved second maternal allele is too small relative to the embryonal DNA to be amplified successfully. Sometimes, in the case of heterozygous maternal genotypes, the maternal allele which was lost during meiosis was still present, albeit with much smaller intensity (Fig. 1b). Either way, for each locus, an outcrossing event was unambiguously scorable by the appearance of a novel, nonmaternal allele, regardless of whether or not the second maternal allele was amplifiable by PCR.

Outcrossing was detected in 58/60 (HO) and 36/37 (MU) of the offspring through the presence of nonmaternal alleles. The corresponding outcrossing rates $0<t \leq 1 \pm 1 \mathrm{SE}$ (assuming a binomial distribution) were $0.96 \pm 0.03(\mathrm{HO})$ and $0.97 \pm 0.029$ (MU). As a result of the high polymorphism displayed by the chosen loci, the expected fraction of nondiscernible outcrosses in the population sample, i.e. of offspring genotypes falsely ascribed to selfing, was small. At $\mathrm{HO}$ and MU, this fraction was only 0.0026 and 0.0007 , respectively. Therefore, the estimate of the outcrossing rate $t$ was not corrected by the expected fraction of ambiguous outcrosses as suggested by Shaw et al. (1981) because it would have changed the numerical value of $t$ by less than 0.005 .

The procedure could be streamlined by restricting the determination of outcrossing rates to the four microsatellite loci with the highest number of alleles per population (loci Zosmar CT-3, GA-2, CT-17H, CT-35). The remaining resolution would still be sufficient to yield an error rate of $\alpha=0.0078$ and 0.005 at $\mathrm{HO}$ and MU, respectively.

Within inflorescences, multiple paternities within sibships occurred in both populations. Coefficients of relatedness $(r \pm \mathrm{SE})$ were calculated as $0.357 \pm 0.059$ (MU) and $0.343 \pm 0.037$ (HO), indicating that offspring represented a mixture of true sibs (expected $r=0.5$ ) and half sibs (expected $r=0.25$ ). For both populations, on average slightly more than two of the three progeny had different fathers.

\section{Discussion}

This study found almost complete outcrossing in two eelgrass Zostera marina populations with predominantly sexual reproduction. Although these findings are concordant with a previous study on the mating systems of Z. marina in the NE Pacific (Ruckelshaus, 1995), mating systems were found to differ among sites from predominantly inbreeding to outcrossing in the seagrass Posidonia australis from Australia (Waycott \& Sampson, 1997). Subaqueous pollination, or hydrophily, has been dis- cussed repeatedly in the light of limited success of fertilization in the aqueous medium (Les, 1988; Cox, 1993; Philbrick \& Les, 1996). The sparse evidence available, mainly from the seagrass species mentioned above and one limnic angiosperm (Philbrick, 1993), neither supports nor rejects a view of ineffective hydrophilous pollination. More data on different species of aquatic plants have to be obtained before generalizations on the reproductive biology will become possible. At least in eelgrass, high outcrossing rates indicate effective crosspollination and, hence, transport of pollen through water motion. In addition, multiple paternities within embryos of the same infructescence suggest that the chances of female flowers receiving foreign pollen are relatively high.

Filiform pollen in eelgrass and many other aquatic angiosperms is interpreted as an adaptation to maximize the capture rate of female stigmata (Cox, 1983). Ackerman $(1997 \mathrm{a}, \mathrm{b})$ extended simple diffusion models of pollen capture and measured the current flow around fertile female flowers. He found that besides direct pollen capture, the fertilization success is enhanced by two additional mechanisms, the rotation of filiforme pollen, and a redirection of water flow towards the female flower downstream. The studies of Ackerman (1997a,b) based on the small-scale hydrodynamics, agree well with the findings of high outcrossing rates in Zostera marina (Ruckelshaus, 1995; this study) using genetic markers.

The outcrossing rates reported here are the highest obtained thus far for a hydrophilous angiosperm. In a previous study conducted in eelgrass, Ruckelshaus (1995) determined the mating system in a perennial population of Zostera marina with an unknown degree of clonal propagation situated in the NE Pacific. She found outcrossing rates $(t \pm \mathrm{SE})$ of $0.905 \pm 0.181$ and $0.776 \pm 0.176$ in 1991 and 1992, respectively, based on 352 and 402 progenies genotyped for two polymorphic allozyme loci. In the present study, 60 and 37 progeny yielded estimates of $t \pm \mathrm{SE}$ of $0.96 \pm 0.03$ and $0.97 \pm 0.029$ at Hooge and Munkmarsch, respectively. As the confidence intervals for the estimates of Ruckelshaus (1995) are relatively wide, it is not possible to evaluate statistically whether outcrossing rates at the present study sites are higher than in the NE Pacific. I expect a higher outcrossing rate in entirely sexually reproducing populations such as Hooge and Munkmarsch than in perennial populations with a mixture of sexual and vegetative propagation. In the absence of clonal growth, matings between consanguineous ramets of identical genotypes are precluded (Handel, 1985). In addition, vigorous tidal currents in the Wadden Sea area may efficiently disperse pollen and foster outcrossing.

The high polymorphism of microsatellite markers in conjunction with their Mendelian (codominant) inheritance make them ideal candidates for the estimation of 
mating system parameters in plants. It was possible to assess whether offspring resulted from selfing or outcrossing using single offspring as units of observation, instead of estimating average rates over entire progeny arrays. Although each outcrossing event can be assessed reliably through the presence of at least one novel allele at any locus, two cases need to be distinguished when offspring carries only maternal alleles: either selfing was correctly inferred, or an outcrossing event was misidentified because the foreign pollen carried alleles identical to the maternal genotypes at all loci. Committing the latter error of not detecting a true outcrossing event would lead to an overestimation of the selfing rate. However, in this study, the associated error probabilities were small in two eelgrass Zostera marina populations, suggesting a potential bias of the outcrossing rates of $<1 \%$. When the polymorphism displayed by the chosen microsatellite markes is high, as in this study, it will be unneccessary to adjust the estimate of $t$ by the expected fraction of nondiscernible outcrosses.

The presented determination of outcrossing rates relies on several assumptions. First, the chosen loci must not be linked, an assumption that can be tested for in each population. Secondly, there must be no specific self-incompatibility associated with any of the pollenmother genotype pairings. Thirdly, pollen genotypes are supposed to be drawn from a random gene pool with uniform gene frequencies. This is a reasonable assumption for a predominantly outcrossing plant such as eelgrass and is not likely to lead to a strong bias in estimates of $t$ in wind- and subaqueous-pollinated plant species in general. In contrast, species with high selfing rates and pronounced genetic substructure within populations will necessitate adjustments for consanguineous matings among genetically related individuals (Ritland, 1984).

Multilocus estimation of mating systems based on the exclusion of discernible outcrossing events was developed in 1981 (Shaw et al., 1981). However, its application was restricted because few plant populations display sufficient variation at traditional Mendelian markers, i.e. allozymes. Microsatellites frequently have $>5$ alleles per locus per population and hence approach sufficient resolution with relatively few loci. In Fig. 2, the error rate $\alpha$ is presented as a function of the number of loci and alleles per locus. The curves reveal that an increase in allele number with a given number of loci rapidly increases the statistical power, more so than an increase in the number of loci assayed. Thus, few (5 or so) microsatellite loci with $\geq 10$ alleles will usually be sufficient for analysing the mating system with $\alpha<0.01$.

Recently, multilocus microsatellite genotyping has been applied to assessing the paternity of tree seedlings (e.g. Dow \& Ashley, 1996). Although the distinction of

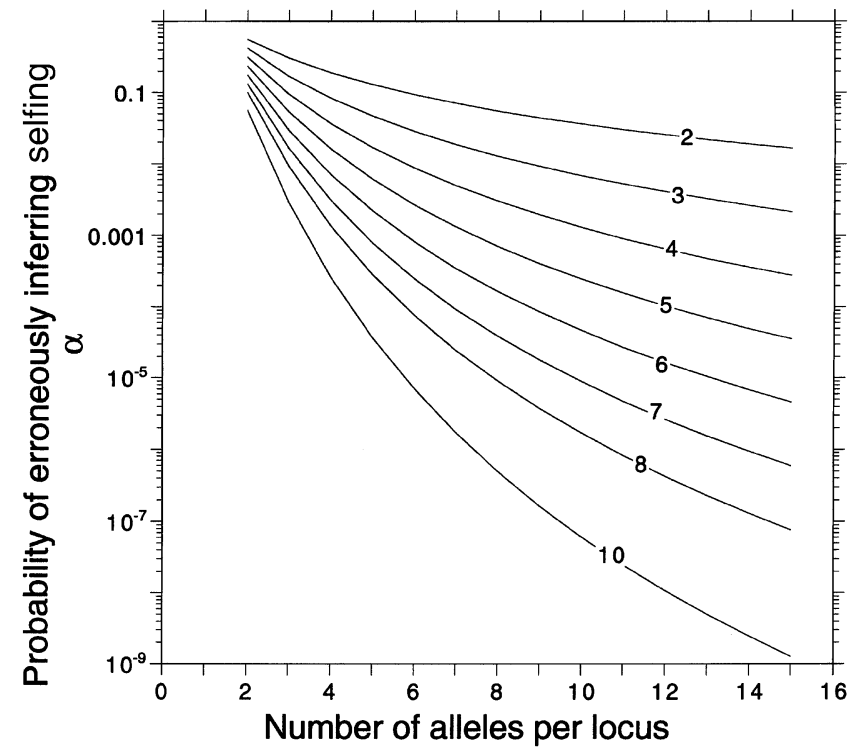

Fig. 2 Curves for theoretical probabilities of erroneously inferring selfing ( $\alpha, \log$-scale) as a function of the number of alleles ( $x$-axis), and for different numbers of loci (different curves). For each locus, the alleles are assumed to have equal frequencies.

self- and foreign-pollen parents is implicit in such studies, to the best of my knowledge, this is the first study devoted entirely to the mating system to use microsatellite markers. One important goal in this study was to genotype the fertilized ovules soon after pollination. This way, it is possible to benefit from the advantages offered by a PCR-based method. Minute amounts of tissue, containing only a few DNA copies, were sufficient to obtain the multilocus genotype of recently fertilized ovules. In contrast, in assays based on allozymes or multilocus DNA fingerprinting (e.g. Vrieling et al., 1997), ripe seeds need to be germinated prior to genotyping. If there is inbreeding depression and selection against ovules resulting from selfing, a nonrandom fraction of offspring is not available for assays which need seedlings for the analysis. In such cases, the mating system estimate will be biased towards more outcrossing. PCR-based methods allow the detection of pollen origin early in the development of seeds. They are therefore better suited to distinguishing post-fertilization processes, such as abortion and selective germination, from each other rather than prefertilization determinants of plant mating systems.

\section{Acknowledgements}

The technical assistance of E. Geissler, S. Liedtke and $\mathrm{M}$. Wegner is gratefully acknowledged. M. Wegner also helped with the field sampling. 


\section{References}

ACKERMAN, J. D. 1997a. Submarine pollination in the marine angiosperm Zostera marina (Zosteraceae). I. The influence of floral morphology on fluid flow. Am. J. Bot., 84, 1099-1109.

ACKERMAN, J. D. 1997b. Submarine pollination in the marine angiosperm Zostera marina (Zosteraceae). II. Pollen transport in flow fields and capture by stigmas. Am. J. Bot., 84, $1110-1119$.

BARRETT, S. C. H., ECKERT, C. G. AND HUSBAND, B. C. 1993. Evolutionary processes in aquatic plant populations. Aquat. Bot., 44, 105-145.

BROWN, A. H. D. AND ALlard, R. W. 1970. Estimation of the mating system in open-pollinated maize populations using isozyme polymorphism. Genetics, 66, 133-145.

CHARLESWORTH, D. AND CHARLESWORTH, B. 1987. Inbreeding depression and its evolutionary consequences. Ann. Rev. Ecol. Syst, 18, 237-268.

Cox, P. A. 1983. Search theory, random motion, and the convergent evolution of pollen and spore morphology in aquatic plants. Am. Nat., 121, 9-31.

CoX, P. A. 1993. Water pollination in plants. Sci. Am., 269, 68-74. DE COCK, A. W. A. M. 1980. Flowering, pollination and fruiting in Zostera marina L. Aquat. Bot., 9, 201-220.

DOW, B. D. AND ASHLEY, M. v. 1996. Microsatellite analysis of seed dispersal and parentage of saplings in bur oak, Quercus macrocarpa. Mol. Ecol., 5, 615-627.

GOODNIGHT, K. F. AND QUELLER, D. C. 1999. RELATEDNESS 5.0.5. Code available at http://www.bioc.rice.edu/ kfg/gsoft.html.

HAMRICK, J. L. AND GODT, M. J. 1991. Allozyme diversity in plant species. In: Brown, A. H. D., Clegg, M. T., Kahler, A. L. and Weir, B. S. (eds) Plant Population Genetics, Breeding, and Genetic Resources, pp. 43-63. Sinauer, Sunderland, MA.

HANDEL, S. N. 1985. The intrusion of clonal growth patterns on plant breeding systems. Am. Nat., 125, 367-384.

LES, D. H. 1988. Breeding systems, population structure, and evolution in hydrophilous angiosperms. Ann. Mo. Bot. Gard., 75, 819-835.

PHILBRICK, C. T. 1993. Underwater cross-pollination in Callitriche hermaphroditica (Callitrichacheae): evidence from random amplified polymorphic DNA markers. Am. J. Bot., 80, 391-394.

PHILBRICK, C. T. AND LES, D. H. 1996. Evolution of aquatic angiosperm reproductive systems. Bioscience, 46, 813-826.

REUSCH, T. B. H. 2000. Five microsatellite loci in eelgrass Zostera marina and a test of cross-species amplification in $Z$. noltii and Z. japonica. Mol. Ecol., 9, 371-373.

QUELler, D. C. AND GOODNIGHT, K. F. 1989. Estimating relatedness using genetic markers. Evolution, 43, 258-275.

REUSCH, T. B. H., STAM, W. T. AND OLSEN, J. L. 1999. Microsatellite loci in eelgrass Zostera marina reveal marked polymorphism within and among populations. Mol. Ecol., 8, 317-322.

REUSCH, T. B. H., STAM, W. T. AND OLSEN, J. L. 2000. A microsatellite-based estimation of clonal diversity and population subdivision in Zostera marina, a marine flowering plant. Mol. Ecol., 9, 127-140.

RITLAND, K. 1984. The effective proportion of self-fertilization with consanguineous matings in inbred populations. Genetics, 106, 139-152.

RITLAND, K. AND JAIN, S. 1981. A model for the estimation of outcrossing rate and gene frequencies using $n$ independent loci. Heredity, 47, 35-52.

RUCKELSHAUS, M. H. 1995. Estimates of outcrossing rates and of inbreeding depression in a population of the marine angiosperm Zostera marina. Mar. Biol., 123, 583-593.

SHAW, D. V., KAHLER, A. L. AND ALLARD, R. W. 1981. A multilocus estimator of mating system parameters in plant populations. Proc. Natl. Acad. Sci. U.S.A., 78, 1298-1302.

VRIELING, K., SAUMITOU-LAPRADE, P., MEELIS, E. AND EPPLEN, J. T. 1997. Multilocus DNA fingerprints in the plant Cynoglossum officinale L. and their use in the estimation of selfing. Mol. Ecol., 6, 587-593.

WALSH, P. S., METZGER, D. A. AND HIGUCHI, R. 1991. Chelex 100 as a medium for simple extraction of DNA for PCR-based typing from forensic material. Biotechniques, 10, 506-513.

WAYCOTT, M. AND SAMPSON, J. F. 1997. The mating system of an hydrophilous angiosperm Posidonia australis (Posidoniaceae). Am. J. Bot., 84, 621-625.

WEIR, B. S. 1996. Genetic Data Analysis II. Sinauer Associates, Sunderland, MA. 